Article

\title{
Evaluation of the Effect of Different Concentrations of Spirotetramat on the Diaspine Scale Parlatoria ziziphi in Citrus Orchards
}

\author{
Amine Assouguem ${ }^{1}{ }^{(D}$, Mohammed Kara $^{2}{ }^{(D}$, Hamza Mechchate $^{3, *(\mathbb{D}}$, Mashail N. AlZain ${ }^{4}$, \\ Omar Mohammed Noman ${ }^{5}$, Hamada Imtara ${ }^{6}$, Christophe Hano ${ }^{7} \mathbb{D}$, Mansour N. Ibrahim ${ }^{8}(\mathbb{D}$, \\ Safaâ Benmessaoud ${ }^{2}$, Abdellah Farah ${ }^{9}$ and Abderahim Lazraq ${ }^{1}$
}

check for

updates

Citation: Assouguem, A.; Kara, M.; Mechchate, H.; AlZain, M.N.; Noman, O.M.; Imtara, H.; Hano, C.; Ibrahim, M.N.; Benmessaoud, S.; Farah, A.; et al. Evaluation of the Effect of Different Concentrations of Spirotetramat on the Diaspine Scale Parlatoria ziziphi in Citrus Orchards. Agronomy 2021, 11, 1840. https:// doi.org/10.3390/agronomy11091840

Academic Editor: Álvaro Rodríguez González

Received: 12 August 2021

Accepted: 11 September 2021

Published: 14 September 2021

Publisher's Note: MDPI stays neutral with regard to jurisdictional claims in published maps and institutional affiliations.

Copyright: (c) 2021 by the authors Licensee MDPI, Basel, Switzerland This article is an open access article distributed under the terms and conditions of the Creative Commons Attribution (CC BY) license (https:// creativecommons.org/licenses/by/ $4.0 /)$
1 Laboratory of Functional Ecology and Environment, Faculty of Sciences and Technology, Sidi Mohamed Ben Abdellah University, Imouzzer Street, Fez P.O. Box 2202, Morocco; assougam@gmail.com (A.A.); lazraqab@gmail.com (A.L.)

2 Laboratory of Biotechnology and Conservation and Valorization of Natural Resources (LBCVRN) (ex LBPRN), Sidi Mohamed Ben Abdellah University, Fez P.O. Box 1796, Morocco; mohammed.kara@usmba.ac.ma (M.K.); Safaa.Benmessaoud@usmba.ac.ma (S.B.)

3 Laboratory of Biotechnology, Environment, Agri-Food, and Health (LBEAS), Faculty of Science Dhar El Mahraz, Sidi Mohamed Ben Abdellah University, Fez P.O. Box 1796, Morocco

4 Department of Biology, College of Sciences, Princess Nourah Bint Abdulrahman University, Riyadh 11451, Saudi Arabia; mnalzain@pnu.edu.sa

5 Department of Pharmacognosy, College of Pharmacy, King Saud University, Riyadh 11451, Saudi Arabia; Onoman20@gmail.com

6 Faculty of Arts and Sciences, Arab American University Palestine, Jenin P.O. Box 240, Palestine; hamada.tarayrah@gmail.com

7 Laboratoire de Biologie des Ligneux et des Grandes Cultures, INRAE USC1328, University of Orleans, CEDEX 2, 45067 Orléans, France; christophe.hano@univ-orleans.fr

8 Department of Agricultural Engineering, College of Food and Agriculture Sciences, King Saud University, Riyadh 11451, Saudi Arabia; malsamee@ksu.edu.sa

9 Laboratory of Applied Organic Chemistry, Faculty of Sciences and Technology, Sidi Mohamed Ben Abdellah University, Imouzzer Street, Fez P.O. Box 2202, Morocco; farah.abdellah1@gmail.com

* Correspondence: Hamza.mechchate@usmba.ac.ma

Abstract: The control of Parlatoria ziziphi (Lucas, 1853) was studied in citrus orchards at Mechraa Belksiri in the Gharb area of Morocco. Three concentrations of spirotetramat $\mathrm{T} 0=0 \mathrm{~L} / \mathrm{Ha}$ as a control experiment, T1 $=0.625 \mathrm{~L} / \mathrm{Ha}, \mathrm{T} 2=0.755 \mathrm{~L} / \mathrm{Ha}$, and T3 $=1 \mathrm{~L} / \mathrm{Ha}$, were applied on 4 ha of Valencia late orchard (each dose for 1 ha of Valencia late). The effect of spirotetramat was evaluated on the mortalities and survival rates of P. ziziphin during the stages of larvae (first instar and second instar) and females (F1, F2, and F3). Results showed that the spirotetramat was effective on larvae and females of $P$. ziziphi. Among the 11,229 females recorded, 93\% were inhibited, while only $7 \%$ were intact after the treatment period. Finally, our study highlights that all concentrations tested were effective on the $P$. ziziphi population; besides, all three concentrations of this product tested were equally effective on larvae and females of $P$. ziziphi. Thus, during the spread period, spraying a low concentration of this product $(0.625 \mathrm{~L} / \mathrm{Ha})$ will better control this pest and reduce the environmental impact.

Keywords: Parlatoria ziziphi; spirotetramat; pest control; Valencia late; crop protection; concentrations; management

\section{Introduction}

In Morocco, the citrus sector is of great importance to socio-economic development, with an estimated production of 2.2 million tons per year [1]. It is mainly produced in Souss, Berkane, Tadla, and Haouz regions, with a total surface area of 126.600 ha [2]. Despite the importance of the citrus sector in the national economy and its particular interest, 
this sector has been seriously affected in recent years by biotic and abiotic factors [3]. In addition to the complications of production and marketing, numerous pest species and diseases reduce the quantity and quality of citrus fruits [4-6].

Among all, the black scale Parlatoria ziziphi (Lucas 1853) (Hemiptera: Diaspididae) is the most destructive pests to citrus. It is a cosmopolitan species and very abundant in citrus orchards in several countries. It originated from Europe and, later, from tropical and subtropical parts of the world on numerous hosts, especially on citrus [7-9].

The black parlatoria scale is one of the most significant pests attacking citrus trees in Morocco [10-12]. This pest causes considerable damage to citrus fruits in the Mediterranean basin and has a negative economic impact that translates into a loss of production in the Maghreb countries, including Morocco [13]. The damage caused by P. ziziphi consists of the weakening and drying of aerial parts of the tree, discoloration of the leaves and fruits, and, most importantly, a commercial loss in the fruits due to the scales fixed on it. Its specific resistance to fruit cleaning aggravates this cosmetic damage. Further, it is one of the most difficult armored scales to control with insecticides [14].

The life cycle of P. ziziphi including the duration of each larval (L1: Mobile larvae on the leaf; L2: Larvae fixed on the leaf), female (F1: Young female of small size with small black scale cover; F2: Female of medium size and medium scale cover; and F3: Adult female with a large scale cover, often carrying eggs), and male (pre-pupa, pupa, and adult) stage is influenced by the host plant, climatic conditions, and interaction with parasitoids $[15,16]$. P. ziziphi lays 10 to 20 eggs. There are two to five generations per year, sometimes six in countries where conditions are more favorable [17].

Spirotetramat (Movento 100 SC, BAYER SA) is a systemic insecticide that contains an active ingredient with a mode of action classified as Group 23 of the Insecticide Resistance Action Committee. It is a compound that belongs to the chemical class of ketoenols, and it is a lipid biosynthesis inhibitor (LBI) [18]. It is active against piercing-sucking insects by acting as an acetyl-CoA carboxylase (ACC) inhibitor, interrupting lipid biosynthesis in the insects $[19,20]$.

In this study, we used field monitoring to investigate the appropriate dose of spirotetramat to control P. ziziphi without disturbing the natural functioning of the agroecosystem. More specifically, we investigated the low effective concentration of spirotetramat on $P$. ziziphi larvae and females inside citrus orchards.

\section{Materials and Methods}

\subsection{Study Area}

This work was carried in Bel Ksiri, Northeast of the Kenitra province, situated on the Gharb plain, North of Morocco (Figure 1). The study area was geographically located at a low altitude ranging from 300 to $500 \mathrm{~m}$ above sea level. The Gharb region is Morocco's largest agricultural area $\left(600 \mathrm{Km}^{2}\right)$ [21]. This region is well known for the production of citrus, cereals, and vegetable cultures due to the appropriate climate and soil properties [22]. The Gharb zone is characterized by the Mediterranean climate with annual precipitations ranging between 480 and $600 \mathrm{~mm}$, and an average temperature of $27^{\circ} \mathrm{C}$ during summer and $13{ }^{\circ} \mathrm{C}$ during winter. 


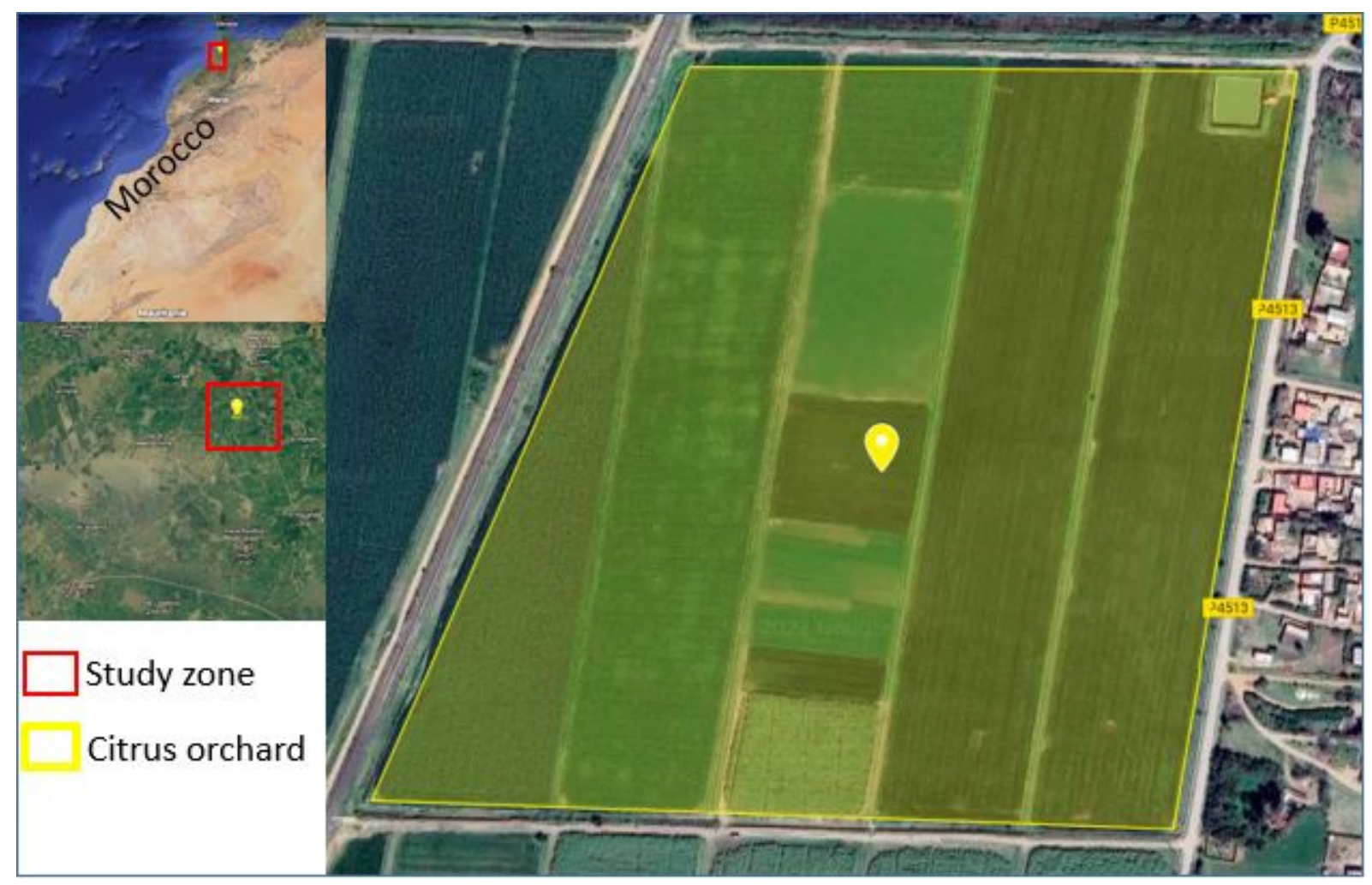

Figure 1. Location of studied orchards [23].

\subsection{Sampling Design}

To investigate the impact of spirotetramat on P. ziziphi, an orchard of 'Valencia Late' (Citrus sinensis) was selected and followed [22]. This product systemic (spirotetramat) has been used because of its effectiveness against a wide range of pests, including the diaspine scale insects, and its reduced damage to the environment and natural enemies. The orchard covers 4 ha on Valencia Late trees. The orchard was divided into 4 plots of 1 ha (Figure 2), and each plot was treated by a specific dose of the pesticide: (i) T0 treated only by water (as a control experiment), (ii) T1 $=0.625 \mathrm{~L} / \mathrm{ha}$, (iii) $\mathrm{T} 2=0.755 \mathrm{~L} / \mathrm{ha}$, and (iv) T3 = $1 \mathrm{~L} /$ ha. In addition, the Teyme Eolo sprayer (Teyme Tecnologia Agricola, Girona, Spain), with its turbulent nozzle and exit diameter of $12 \mathrm{~mm}$, delivered $1.55 \mathrm{~L} / \mathrm{min}$ at a pressure of 20 bars. In addition, $2500 \mathrm{~L}$ of spray liquid were sprayed by a towed atomizer on each plot (1 ha), at a rate of $6 \mathrm{~L}$ of spray for each tree (Figure 2). These 3 concentrations were used based mainly on the quantities of pesticides used by local farmers.

To evaluate the effect of each concentration after treatment ( 1 to 8 weeks), 200 leaves of Valencia late trees in each plot were collected weekly and randomly from the different directions of the tree (North, East, South, and West), for a total of 20 trees by the plot that belonged to a square block ( 3 repetitions were performed independently). We left 2 lines between the different plots treated with spirotetramat. Then, we count the mortalities (M) and survival rates (V) of P. ziziphi at two stages: Larvae (L1 and L2) and females (F1, F2, and F3) on each leaf surface.

In the laboratory, the different stages of $P$. ziziphi on each leaf were determined and counted on both leaf surfaces; we counted the survival rates (V) and mortalities (M) of $P$. ziziphi at two larval stages (L1 and L2) and three generations of female (F1, F2, and F3) using a binocular microscope. 


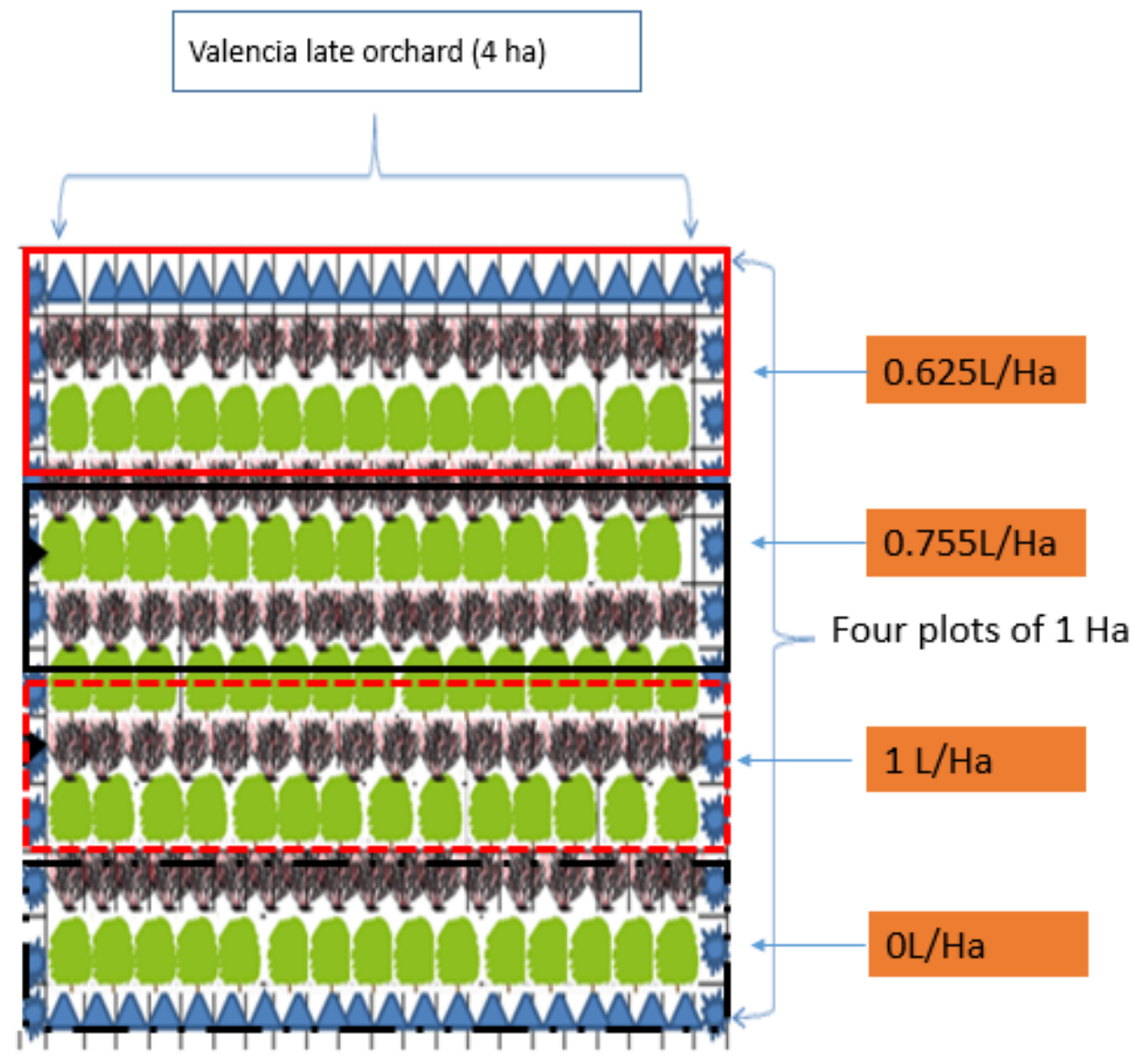

Figure 2. Model of the monitored orchard (divided into four small plots of 1 ha) and used doses of spirotetramat $(\mathrm{T} 0=0 \mathrm{~L} / \mathrm{ha}, \mathrm{T} 1=0.625 \mathrm{~L} / \mathrm{ha}, \mathrm{T} 2=0.755 \mathrm{~L} / \mathrm{ha}$, and T3 $=1 \mathrm{~L} / \mathrm{ha})$.

\subsection{Statistics}

Statistics of data were done in Minitab software, version 1.1.19, LLC, USA. The results were given as mean $\pm \mathrm{SD}$. Moreover, to evaluate the effectiveness of spirotetramat, we calculated the survival (survived specimens/total sampled specimens) and mortality (inhibited specimens/total sampled specimens) of P. ziziphi for both larvae and females [23]. We checked for normality and homogeneity of variance for all variables with the KolmogorovSmirnov test. To assess the difference between the survival rates and mortalities between different stages of P. ziziphi, we used the independent t-test, considering the two stages as unrelated variables, while the effect of different doses of the systemic product was tested by the ANOVA One-way test followed by a post hoc Tukey test at $p<0.05$. The linear correlation between different larvae and female stages was obtained by the Pearson correlation coefficient at $p<0.05$. Principal component analyses were accomplished to elucidate the relationship between the treatment and different stages of P. ziziphi.

\section{Results}

\subsection{Impact on Larvae}

Out of 3965 larvae, $83 \%$ were inhibited, and only $17 \%$ survived after the treatment period. Specifically, during the first instar larval (L1) stage, 620 survived $(16 \%)$, while 2234 were suppressed (56\%). Moreover, in the second instar larval (L2) stage, 53 larvae survived $(1 \%)$ and 1058 larvae were inhibited $(27 \%)$. On the other hand, survival and mortality rates were very high during larval stage 1 (Figure 3), while these two parameters were low during larval stage 2 . Mortalities and survival rates were uncorrelated during both stages (Table 1). 


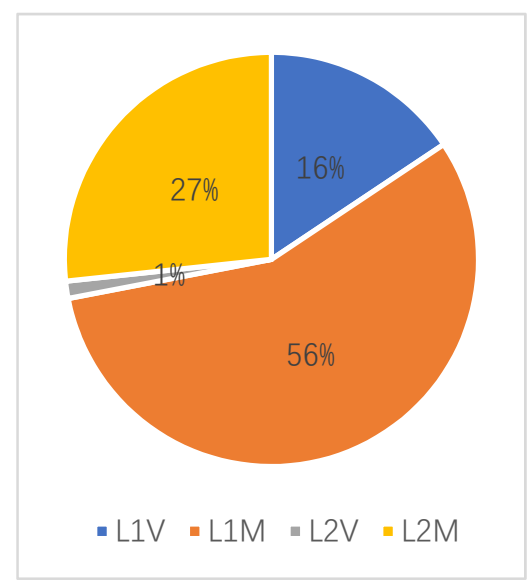

Figure 3. Comparison of mortalities (M) and survival rates (V) during two larvae stages of P. ziziphi (L1V: Surviving larvae of stage 1; L1M: Dead larvae of stage 1; L2V: Surviving larvae of stage 2; L2M: Dead larvae of stage 2).

Table 1. Relationship between the different stages of P. ziziphi.

\begin{tabular}{cccccccccc}
\hline & L1V & L1M & L2V & L2M & F1V & F1M & F2V & F2M & F3V \\
\hline L1M & -0.197 & & & & & & & & \\
L2V & 0.344 & -0.390 & & & & & & & \\
L2M & -0.396 & 0.036 & -0.178 & & & & & & \\
F1V & 0.445 & -0.406 & 0.779 & -0.352 & & & & & \\
F1M & -0.244 & -0.122 & -0.323 & 0.256 & -0.268 & & & & \\
F2V & 0.269 & -0.462 & 0.550 & -0.204 & 0.580 & -0.170 & & \\
F2M & -0.389 & 0.117 & -0.451 & 0.440 & -0.452 & 0.599 & -0.269 & & \\
F3V & 0.348 & -0.296 & 0.542 & -0.275 & 0.589 & -0.283 & 0.860 & -0.429 & \\
F3M & -0.336 & 0.126 & -0.390 & 0.296 & -0.374 & 0.312 & -0.099 & 0.617 & -0.103 \\
\hline
\end{tabular}

Regarding the efficacy of the doses on the different larval stages, all concentrations of spirotetramat tested were effective on stage 1 larvae survivors (L1V) with the means of $\mathrm{T} 1=10.00^{\mathrm{B}} \pm 3.30, \mathrm{~T} 2=7.75^{\mathrm{B}} \pm 3.17$, and $8.08^{\mathrm{B}} \pm 2.49$, while the $\mathrm{T} 3$ dose was very effective on stage 1 dead larvae (L1M) with an average of $41.13^{B} \pm 10.82$. Further, all the tested doses (T1, T2, and T3) were effective against stage 2 larvae (Table 2). Furthermore, all doses of this systemic product were positively correlated with second instar larval Inhibited (L2M) specimens. The T3 concentration was positively correlated with first instar larval Inhibited (L1M) specimens. In contrast, all doses tested were negatively correlated with surviving larvae of the first instar and second instar (L1V and L2V) (Figure 4).

Table 2. Survival (V) and mortality (M) of Parlatoria ziziphi larvae (L1,L2) treated with different doses of spirotetramat T0 $=0 \mathrm{~L} / \mathrm{ha}, \mathrm{T} 1=0.625 \mathrm{~L} / \mathrm{ha}, \mathrm{T} 2=0.755 \mathrm{~L} / \mathrm{ha}$, and T3 $=1 \mathrm{~L} / \mathrm{ha}$.

\begin{tabular}{ccccc}
\hline & L1V & L1M & L2V & L2M \\
\hline T0 & $14.13^{\mathrm{A}} \pm 4.79$ & $21.13^{\mathrm{A}} \pm 7.96$ & $3.42^{\mathrm{A}} \pm 1.67$ & $9.13^{\mathrm{A}} \pm 5.90$ \\
\hline T1 & $10.00^{\mathrm{B}} \pm 3.30$ & $27.92^{\mathrm{A}} \pm 10.60$ & $1.00^{\mathrm{B}} \pm 1.38$ & $14.42^{\mathrm{B}} \pm 5.24$ \\
\hline T2 & $7.75^{\mathrm{B}} \pm 3.17$ & $24.04^{\mathrm{A}} \pm 7.32$ & $0.67^{\mathrm{B}} \pm 0.87$ & $13.71^{\mathrm{B}} \pm 4.51$ \\
\hline T3 & $8.08^{\mathrm{B}} \pm 2.49$ & $41.13^{\mathrm{B}} \pm 10.82$ & $0.54^{\mathrm{B}} \pm 0.59$ & $15.96^{\mathrm{B}} \pm 4.43$
\end{tabular}

Means in the same column with different superscripts are significantly different $(p<0.05)$.

Figure 5 shows that the survival means of the larval stage in the untreated plot increased significantly from week $1\left(15.67^{\mathrm{AB}} \pm 2.06\right)$ to week $8\left(22.67^{\mathrm{A}} \pm 1.15\right)$. On the other hand, the average for surviving larvae remained low for all weeks after treatment with all concentrations of spirotetramat (Table 3). 

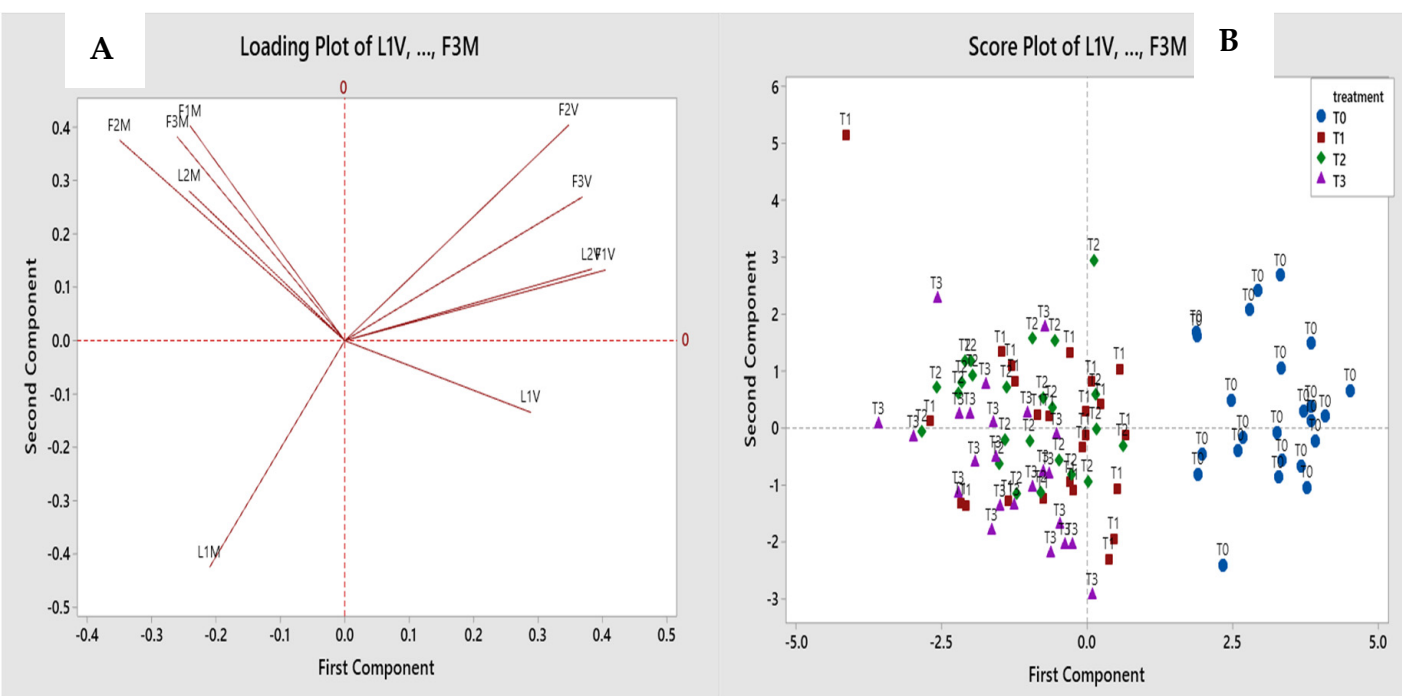

Figure 4. Principal component analysis (PCA) of the different stages of P. ziziphi according to the different treatment rates (A); double projection diagram for the two components (B).

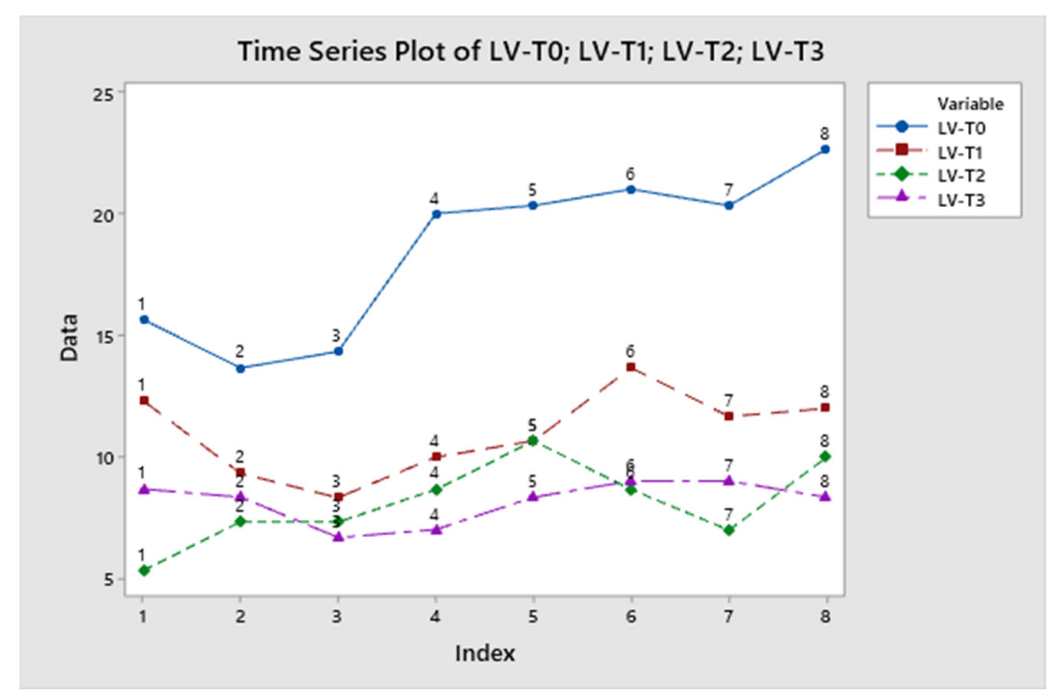

Figure 5. Evolution of the larvae survival of Parlatoria ziziphi according to different follow-up dates after treatment.

Table 3. Survival (V) of Parlatoria ziziphi larvae treated with different doses of spirotetramat $(\mathrm{T} 0=0 \mathrm{~L} / \mathrm{ha}, \mathrm{T} 1=0.625 \mathrm{~L} / \mathrm{ha}, \mathrm{T} 2=0.755 \mathrm{~L} / \mathrm{ha}$, and T3 $=1 \mathrm{~L} / \mathrm{ha}$ ) according to different followup dates after treatment.

\begin{tabular}{ccccc}
\hline & LV-TO & LV-T1 & LV-T2 & LV-T3 \\
\hline Week 1 BT & $15.67^{\mathrm{AB}} \pm 2.06$ & $12.33^{\mathrm{A}} \pm 2.31$ & $5.33^{\mathrm{A}} \pm 1.31$ & $8.66^{\mathrm{A}} \pm 0.57$ \\
\hline Week 2 BT & $13.67^{\mathrm{B}} \pm 0.57$ & $9.33^{\mathrm{A}} \pm 1.53$ & $7.33^{\mathrm{A}} \pm 1.52$ & $8.33^{\mathrm{A}} \pm 0.57$ \\
\hline Week 3 BT & $14.33^{\mathrm{B}} \pm 2.62$ & $8.33^{\mathrm{A}} \pm 2.51$ & $7.33^{\mathrm{A}} \pm 1.15$ & $6.67^{\mathrm{A}} \pm 4.51$ \\
\hline Week 4 BT & $20.00^{\mathrm{AB}} \pm 2.65$ & $10.00^{\mathrm{A}} \pm 2.57$ & $8.67^{\mathrm{A}} \pm 2.52$ & $7.00^{\mathrm{A}} \pm 1.00$ \\
\hline Week 5 BT & $20.33^{\mathrm{AB}} \pm 2.31$ & $10.68^{\mathrm{A}} \pm 1.52$ & $10.67^{\mathrm{A}} \pm 2.50$ & $12.00^{\mathrm{A}} \pm 3.00$ \\
\hline Week 6 BT & $21.00^{\mathrm{AB}} \pm 2.65$ & $13.67^{\mathrm{A}} \pm 2.21$ & $8.67^{\mathrm{A}} \pm 1.16$ & $9.00^{\mathrm{A}} \pm 1.73$ \\
\hline Week 7 BT & $20.33^{\mathrm{AB}} \pm 2.08$ & $11.67^{\mathrm{A}} \pm 1.04$ & $7.00^{\mathrm{A}} \pm 1.73$ & $9.00^{\mathrm{A}} \pm 2.00$ \\
\hline Week 8BT & $22.67^{\mathrm{A}} \pm 1.15$ & $12.00^{\mathrm{A}} \pm 2.45$ & $8.33^{\mathrm{A}} \pm 1.15$ & $8.33^{\mathrm{A}} \pm 1.55$ \\
\hline
\end{tabular}

Means in the same column with different superscripts are significantly different $(p<0.05)$. 


\subsection{Impact on Females}

Among the 11,229 females recorded (Figure 6), 93\% $(n=10,473)$ were inhibited, while only $7 \%(n=756)$ were intact after the treatment period. Specifically, during the F1 generation, only $1 \%(n=76)$ survived, while $14 \%(n=1574)$ were inhibited. Furthermore, during the F2 generation, $2 \%(n=225)$ survived and 30\% $(n=3377)$ were eliminated. Similarly, $4 \%(n=455)$ survived and $49 \%(n=5522)$ were inhibited during the F3 generation.

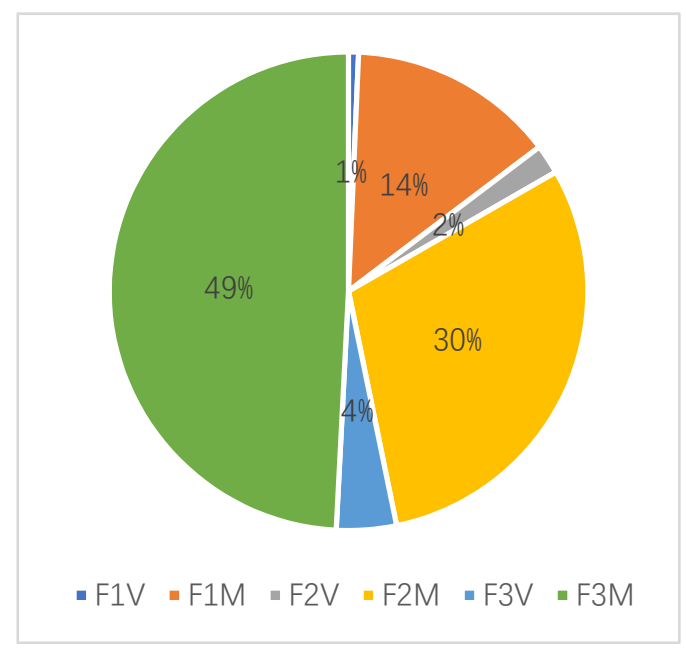

Figure 6. Comparison of mortalities (M) and survival rates $(\mathrm{V})$ during three female stages of $P$. ziziphi. (F1V: Survived females of stage 1; F1M: Dead females of stage 1; F2V: Surviving females of stage 2; F2M: Dead females of stage 2; F3V: Surviving females of stage 3; F3M: Dead females of stage 3).

In terms of comparisons between stages, the means of surviving females were higher in F3, followed by F2 and then F1. Similarly, inhibited females were more numerous in F3, followed by F2 and F1. On the other hand, survival averages were variable for all periods. Similarly, the means of females eliminated from the three stages were significantly different during the entire follow-up period (Table 4).

Table 4. Survival (V) and mortality (M) of Parlatoria ziziphi females (F1, F2, and F3) treated with different doses of spirotetramat $(\mathrm{T} 0=0 \mathrm{~L} / \mathrm{ha}, \mathrm{T} 1=0.625 \mathrm{~L} / \mathrm{ha}, \mathrm{T} 2=0.755 \mathrm{~L} / \mathrm{ha}$, and T3 $=1 \mathrm{~L} / \mathrm{ha})$.

\begin{tabular}{ccccccc}
\hline & F1V & F1M & F2V & F2M & F3V & F3M \\
\hline T0 & $6.08^{\mathrm{A}} \pm 2.59$ & $13.38^{\mathrm{B}} \pm 4.86$ & $9.43^{\mathrm{A}} \pm 3.51$ & $27.88^{\mathrm{A}} \pm 6.40$ & $16.88^{\mathrm{A}} \pm 5.71$ & $64.50^{\mathrm{A}} \pm 15.71$ \\
\hline T1 & $1.38^{\mathrm{B}} \pm 1.17$ & $23.21^{\mathrm{A}} \pm 11.33$ & $3.29^{\mathrm{B}} \pm 2.45$ & $43.42^{\mathrm{B}} \pm 14.27$ & $6.67^{\mathrm{B}} \pm 3.10$ & $76.54^{\mathrm{A}} \pm 22.41$ \\
\hline T2 & $1.13^{\mathrm{B}} \pm 0.99$ & $24.00^{\mathrm{A}} \pm 6.08$ & $3.50^{\mathrm{B}} \pm 2.41$ & $49.92^{\mathrm{B}} \pm 11.55$ & $5.92^{\mathrm{B}} \pm 3.41$ & $77.04^{\mathrm{A}} \pm 22.01$ \\
\hline T3 & $0.67^{\mathrm{B}} \pm 0.90$ & $18.38^{\mathrm{A} B} \pm 7.57$ & $2.58^{\mathrm{B}} \pm 2.55$ & $47.38^{\mathrm{B}} \pm 16.05$ & $6.83^{\mathrm{B}} \pm 2.20$ & $76.50^{\mathrm{A}} \pm 23.29$ \\
\hline
\end{tabular}

Means that do not share a letter are significantly different.

The three doses were all effective on the survival rates of females in all three stages $(\mathrm{F} 1 \mathrm{~V}$, $\mathrm{F} 2 \mathrm{~V}$, and $\mathrm{F} 3 \mathrm{~V}$ ) with averages of $\mathrm{T} 1=1.38^{\mathrm{B}} \pm 1.17, \mathrm{~T} 2=1.13^{\mathrm{B}} \pm 0.99$, and $\mathrm{T} 3=0.67^{\mathrm{B}} \pm 0.90$. The concentrations $\mathrm{T} 1=23.21^{\mathrm{A}} \pm 11.33$ and $\mathrm{T} 2=24.00^{\mathrm{A}} \pm 6.08$ were effective on stage 1 dead females (F1M). What is more, all doses of this systemic product tested were effective on dead females of stage $2(\mathrm{~F} 2 \mathrm{M})$ with the averages $\mathrm{T} 1=43.42^{\mathrm{B}} \pm 14.27, \mathrm{~T} 2=49.92^{\mathrm{B}} \pm 11.55$, and $\mathrm{T} 3=47.38^{\mathrm{B}} \pm 16.05$, while spirotetramat showed no effect on stage 3 females (F3M) (Table 4). In addition, the doses of this systemic product were positively correlated with inhibited females of all stages (F1M, F2M, and F3M), while all doses tested were negatively correlated with surviving females (F1V, F2V, and F3V) (Figure 4).

Figure 7 shows that female survival in the untreated plot decreased significantly from week $1\left(46.00^{\mathrm{A}} \pm 5.56\right)$ to week $8\left(28.00^{\mathrm{B}} \pm 2.0014 .33^{\mathrm{AB}} \pm 2.45\right)$. While the mean survival 
of females in the $0.625 \mathrm{~L} /$ ha treated plot was very high in the first week after treatment $\left(21.00^{\mathrm{A}} \pm 2.31\right)$, the means then decreased significantly over the last 7 weeks after treatment to $\left(14.33^{\mathrm{AB}} \pm 2.45\right)$ in week 8 (Table 5). The survival averages of the females remained low for all 8 weeks after treatment with the concentrations $0.755 \mathrm{~L} /$ he and $1 \mathrm{~L} /$ he (Table 5 ).

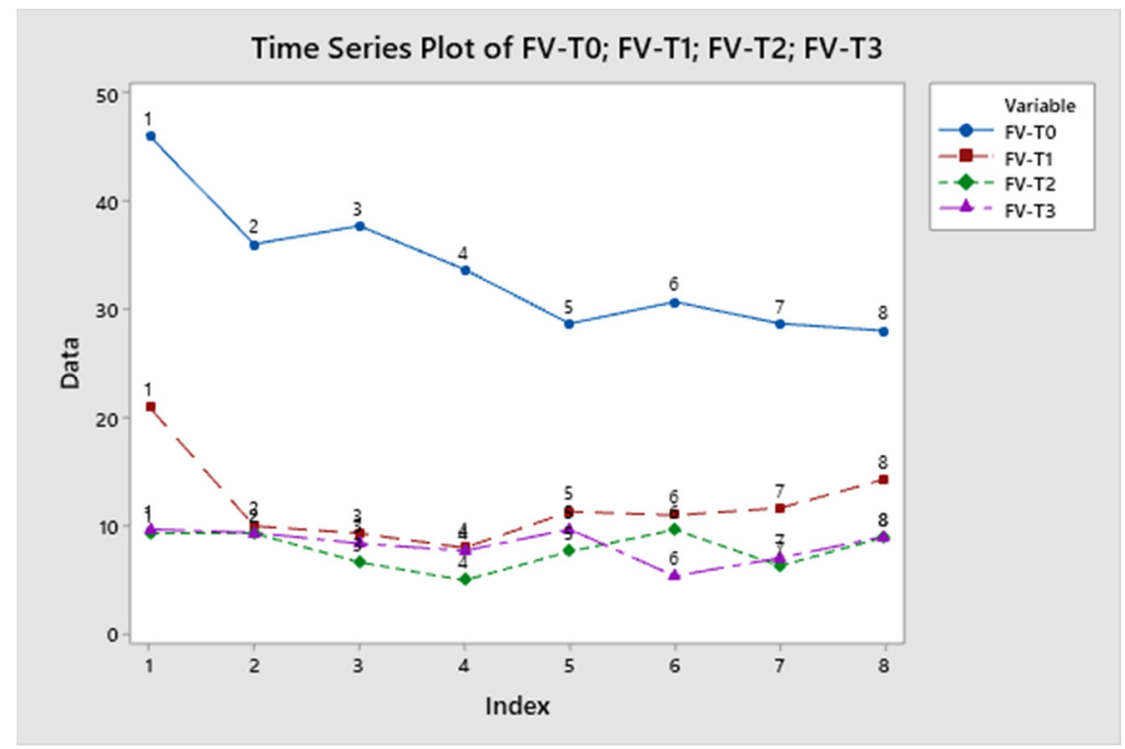

Figure 7. Evolution of females' survival of Parlatoria ziziphi according to the different follow-up dates after treatment.

Table 5. Survival (V) of Parlatoria ziziphi females treated with different doses of spirotetramat $(\mathrm{T} 0=0 \mathrm{~L} / \mathrm{ha}, \mathrm{T} 1=0.625 \mathrm{~L} / \mathrm{ha}, \mathrm{T} 2=0.755 \mathrm{~L} / \mathrm{ha}$, and T3 $=1 \mathrm{~L} / \mathrm{ha})$ according to different follow-up dates after treatment.

\begin{tabular}{ccccc}
\hline & FV-TO & FV-T1 & FV-T2 & FV-T3 \\
\hline Week 1 BT & $46.00^{\mathrm{A}} \pm 5.56$ & $21.00^{\mathrm{A}} \pm 2.31$ & $9.33^{\mathrm{A}} \pm 0.58$ & $9.68^{\mathrm{A}} \pm 0.57$ \\
\hline Week 2 BT & $36.00^{\mathrm{AB}} \pm 5.33$ & $10.00^{\mathrm{B}} \pm 1.53$ & $9.33^{\mathrm{A}} \pm 1.53$ & $9.33^{\mathrm{A}} \pm 0.57$ \\
\hline Week 3 BT & $37.67^{\mathrm{AB}} \pm 3.21$ & $9.33^{\mathrm{B}} \pm 2.51$ & $6.67^{\mathrm{A}} \pm 1.53$ & $8.33^{\mathrm{A}} \pm 4.51$ \\
\hline Week 4 BT & $33.67^{\mathrm{AB}} \pm 2.52$ & $8.00^{\mathrm{B}} \pm 0.57$ & $5.00^{\mathrm{A}} \pm 1.73$ & $7.67^{\mathrm{A}} \pm 1.00$ \\
\hline Week 5 BT & $28.67^{\mathrm{B}} \pm 2.08$ & $11.33^{\mathrm{B}} \pm 1.52$ & $7.67^{\mathrm{A}} \pm 1.52$ & $9.66^{\mathrm{A}} \pm 3.00$ \\
\hline Week 6 BT & $30.67^{\mathrm{B}} \pm 2.89$ & $11.00^{\mathrm{B}} \pm 2.21$ & $9.67^{\mathrm{A}} \pm 2.31$ & $5.33^{\mathrm{A}} \pm 1.73$ \\
\hline Week 7 BT & $28.67^{\mathrm{B}} \pm 4.04$ & $11.67^{\mathrm{B}} \pm 1.04$ & $6.33^{\mathrm{A}} \pm 1.15$ & $7.00^{\mathrm{A}} \pm 2.00$ \\
\hline Week 8 BT & $28.00^{\mathrm{B}} \pm 2.00$ & $14.33^{\mathrm{AB}} \pm 2.45$ & $9.00^{\mathrm{A}} \pm 2.65$ & $9.00^{\mathrm{A}} \pm 1.55$ \\
\hline
\end{tabular}

Means that do not share a letter are significantly different.

\section{Discussion}

Based on our nationwide survey, this is the first research on the control of P. ziziphi using a systemic product, spirotetramat. Our main objective was to provide detailed and extensive data on the efficacy of this systemic product in controlling this pest. These results are the first and only data supplied in the control of P. ziziphi in citrus in North Africa, which is of great importance for further comparative research and the adoption of less environmentally damaging and more effective doses to control the pest.

Our results showed that in the larval stage, inhibition was nearly $83 \%$, while in females, the inhibition rate was more than $92 \%$. All three doses tested were effective on the survival rates of females in all three stages (F1V, F2V, and F3V) during the whole follow-up period, and the same results were reported by [24], where spraying spirotetramate on citrus fruit reduced the survival rate and fecundity of the mealybug (Lepidosaphes beckii) to 100\% 
172 days after treatment. In addition, spirotetramat showed no effect on the mortality rates of stage 3 females (F3M). This may be due to other unknown factors that contributed to the increased mortality in the untreated plot. In Egypt, the same results were reported on navel orange trees, Citrus sinensis, which reported high mortality due to unknown factors [7]. All doses of spirotetramat tested were effective on stage 1 larvae, while the T3 concentration was very effective on stage 2 larvae. According to the findings of Nauen [25], spirotetramat causes death in larvae deposited by adult female aphids after $24 \mathrm{~h}$ of its application. At the larval stages, the efficacy of the doses used was variable. Regarding the mortality rate, the T3 concentration ( $1 \mathrm{~L} /$ he) was effective against larva 1 , while all three doses tested were effective on the survival rate of larva 1, while on larva stage 2, all concentrations showed the same efficacy. Our objective was to search for lower concentrations of pesticides that have effective control against $P$. ziziphi. This will reduce pesticide use and avoid pesticide resistance [26-28]. Therefore, for easy marketing, the remaining residues are suggested to be less on treated fruits [29,30].

Among the total population of 15,194 treated with this systemic product, $90.59 \%$ were inhibited, and only $9.41 \%$ were intact after treatment. Similar results were reported in Morocco and Algeria where spirotetramat controlled Parlatoria pergandii with encouraging results in the citrus orchard [23,31]. All doses of spirotetramat used showed a significant effect on larvae and females of P. Ziziphi. All the concentrations of spirotetramat used were effective on the population of Parlatoria blanchardi of date palm. Among all concentrations tested, we noticed that the survival rate remained low for 8 weeks after the application of the treatment. According to [24], spirotetramat spraying on citrus fruit resulted in $100 \%$ lower survival and fecundity of Lepidosaphes beckii for 172 days after treatment. Therefore, the choice of the right concentration remains a necessity in order to preserve the agroecosystem. In general, large amounts of pesticides control pests but negatively influence natural enemies and the environment [32]. In contrast, the combination of the effect of parasitism (natural enemies) and low doses of pesticides would provide effective and environmentally friendly pest control [23].

\section{Conclusions}

Our findings highlight two key messages: (1) The data indicated that spirotetramat was effective on larvae and females of $P$. ziziphi and (2) all doses tested were effective on the $P$. ziziphi population. Since spirotetramat is an effective and widely used pesticide, further studies on its effect on other natural enemy populations and the residues remaining on fruits are needed to establish appropriate management strategies.

Author Contributions: Conceptualization, A.A. and A.L.; methodology, A.A., M.K., and H.M.; validation, H.I. and A.F.; investigation, A.A.; data curation, M.N.A., O.M.N., and C.H.; writing-original draft preparation, A.A. and H.M.; review and editing, M.N.I. and S.B.; supervision, A.L. and A.F. All authors have read and agreed to the published version of the manuscript.

Funding: This research was funded by the Deanship of Scientific Research at Princess Nourah bint Abdulrahman University through the Fast-track Research Funding Program.

Institutional Review Board Statement: Not applicable.

Informed Consent Statement: Not applicable.

Data Availability Statement: Data are available upon request.

Acknowledgments: The authors are thankful to the Deanship of Scientific Research at Princess Nourah bint Abdulrahman University for the support of this research through the Fast-track Research Funding Program.

Conflicts of Interest: The authors declare no conflict of interest. 


\section{References}

1. ASPAM Campagne Agrumicole 2020-2021: Les Professionnels Tablent Sur Des Exportations de 630,000 Tonnes—La Vie Éco. 2021. Available online: https:/ / www.lavieeco.com/ (accessed on 6 June 2021).

2. Smaili, M.C.; Boutaleb-Joutei, A.; Blenzar, A. Beneficial Insect Community of Moroccan Citrus Groves: Assessment of Their Potential to Enhance Biocontrol Services. Egypt J. Biol. Pest Control 2020, 30, 1-15. [CrossRef]

3. Smaili, M.C.; Blenzar, A.; Boutaleb, J.A. Facteurs de Mortalité Du Puceron Noir de l'oranger Toxoptera Aurantii Boyer de Fonscolombe (Hemiptera: Aphididae) Sur Agrumes Dans La Région Nord Du Gharb. Du Symposium Méditerranéen Sur La Protection Phytosanitaire Des Agrumes Rabat, Maroc. Available online: https://scholar.google.com/scholar?hl=fr\&as_sdt= $0 \% 2 \mathrm{C} 5 \& q=$ Smaili $\% 2 \mathrm{C}+\mathrm{M} .+\mathrm{C} . \% 2 \mathrm{C}+$ Blenzar $\% 2 \mathrm{C}+\mathrm{A} . \% 2 \mathrm{C}+\% 26+$ Boutaleb $\% 2 \mathrm{C}+\mathrm{J} .+\mathrm{A} .+\% 282008 \% 29 .+$ Facteurs + de + mortalit $\%$ $\mathrm{C} 3 \% \mathrm{~A} 9+\mathrm{du}+$ puceron+noir+de+1 $\%$ E2 $\% 80 \% 99$ oranger+Toxoptera+aurantii + Boyer + de+Fonscolombe+ $\% 28 \mathrm{Hemiptera} \% 3 \mathrm{~A}+$ Aphididae\%29+sur+agrum (accessed on 10 July 2021).

4. Mazih, A. Status of Citrus IPM in the Southern Mediterranean Basin Morocco, North Africa. Acta Hortic. 2015, 1065, 1097-1104. [CrossRef]

5. Smaili, M.C. Current Pest Status and the Integrated. Available online: https://scholar.google.com/scholar?hl=fr\&as_sdt=0\%2C5 $\& q=$ Smaili + MC+\%282017\%29+Current+pest+status+and+the+integrated+pest+management+strategy+in+the+citrus+groves + in+Morocco. $+\mathrm{In} \% 3 \mathrm{~A}+\mathrm{Abstracts}+\mathrm{of}+$ the $+\mathrm{IOBC}+$ citrus+working+group+meeting+on+citrus+pests $\% 2 \mathrm{C}+$ diseaa (accessed on 10 July 2021).

6. Smaili, M.C.; Afellah, M.; Zrida, L. Contribution à La Mise En Place d'un Système de Lute Intégrée Sur Clémentinier Dans La Région Du Gharb. Available online: https: / / scholar.google.com/scholar?hl=fr\&as_sdt=0\%2C5\&q=Smaili+MC $\% 2 \mathrm{C}+\mathrm{Afellah}+\mathrm{M} \%$ 2C+Aarab+A+\%282001\%29+Biologie $\% 2 \mathrm{C}+\% \mathrm{C} 3 \%$ A 9 cologie+et+lutte+biologique+contre+Phyllocnistis+citrella+Stain.+sur+ $\mathrm{cl} \% \mathrm{C} 3 \% \mathrm{~A} 9$ mentinier+dans+la+r\%C3\%A9gion+du+Gharb.+In+\%3A+Abstracts+of +the+\%E2\%80\%9CI+Coll+de (accessed on 10 July 2021).

7. Awadalla, S.; Bayoumy, M.H.; El-Metwally, M.; Alhussieny, R. Population and Mortality Studies on the Black Scale Insect, Parlatoria ziziphi (Lucas) (Hemiptera: Diaspididae) in an Egyptian Citrus Orchard. J. Plant Prot. Pathol. 2021, 12, 197-202. [CrossRef]

8. Tawfeek, M.E.; Abu-shall, A.M.H. Seasonal Population Dynamics of Parlatoria ziziphus (Lucas) (Homoptera: Diaspididae) in Menoufia Gavernorate, Egypt. Alex. Sci. Exch. J. Int. Q. J. Sci. Agric. Environ. 2010, 31, 331-338. [CrossRef]

9. Ferris, G.F. Atlas of the Scale Insects of North America. Nature 1937, 151, 657. [CrossRef]

10. Abbassi, M.I. Notes Bio-Écologiques Sur Parlatoria pergandii Au Maroc. Fruits 1975, 30, 179-184.

11. Smirnoff, W. The Citrus Black Scale in Morocco. Terre Maroc. 1950, 24, 457-460.

12. Smaili, M.C.; Abbassi, M.; Boutaleb, J.A.; Blenzar, A. Richesse Spécifique Des Ennemis Naturels Associés Aux Vergers d'agrumes Au Maroc: Intérêt et Implication Pour La Lutte Biologique. EPPO Bull. 2013, 43, 155-166. [CrossRef]

13. Tena, A.; García-Marí, F. Current Situation of Citrus Pests and Diseases in the Mediterranean Basin. IOBCwprs Bull 2011, 62, 365-378.

14. Haddad, D.N.; Sadoudi, F.G.-M. Management of a main citrus pest black parlatoria scale Parlatoria ziziphi (lucas) (hemiptera: Diaspididae) in the mediterranean basin. SciFed Virol. Res. J. 2018, 1, 184-199. [CrossRef]

15. Kemayou, C.M.; Nono, C.T.; Audrey, V.V. Bio-Ecology of Black Scale Insects Parlatoria ziziphi Lucas (Homoptera: Bio-Ecology of Black Scale Insects Parlatoria ziziphi Lucas (Homoptera: Diaspididae) on Three Varieties of Mandarin Trees in a Foumbot Orchard (West Cameroon) 2020. Available online: https:/ / entomoljournal.com (accessed on 8 June 2021).

16. Polaszek, A. The Egyptian Species of Encarsia (Hymenoptera: Aphelinidae): A Preliminary Review. Zool. Meded. 1999, 73, 131-163.

17. Sweilem, S.M.; El-Bolok, M.M.; Abdel-Aleem, R.Y. Biological Studies on Parlatoria zizyphus (Lucas) (Homoptera—Diaspididae). Available online: http://www.sidalc.net/cgi-bin/wxis.exe/?IsisScript=orton.xis\&method=post\&formato=2\&cantidad=1\& expresion $=\mathrm{mfn}=073700$ (accessed on 23 August 2021).

18. Planes, L.; Catalán, J.; Tena, A.; Porcuna, J.L.; Jacas, J.A.; Izquierdo, J.; Urbaneja, A. Lethal and Sublethal Effects of Spirotetramat on the Mealybug Destroyer, Cryptolaemus Montrouzieri. J. Pest Sci. 2012, 86, 321-327. [CrossRef]

19. Kühnhold, A.M.J.; Klueken, L.D.M. Movento®, an Innovative Solution for Sucking Insect Pest Control in Agriculture: Field Performance in Fruits and Vegetables. Available online: https:/ /scholar.google.com/scholar?hl=fr\&as_sdt=0\%2C5\&q=Kuhnhold+ et + al. $\% 2 C+2008 \& b \operatorname{tnG}=$ (accessed on 24 July 2021).

20. Mohapatra, S.; Deepa, M.; Jagadish, G.K. An Efficient Analytical Method for Analysis of Spirotetramat and Its Metabolite Spirotetramat-Enol by HPLC. Bull. Environ. Contam. Toxicol. 2011, 88, 124-128. [CrossRef] [PubMed]

21. Hassouni, T.; Belghyti, D. Distribution of Gastrointestinal Helminths in Chicken Farms in the Gharb Region-Morocco. Parasitol. Res. 2006, 99, 181-183. [CrossRef] [PubMed]

22. Benyahia, H.; Talha, A.; Fadli, A.; Chetto, O.; Omari, F.E.; Beniken, L. Performance of 'Valencia Late' Sweet Orange (Citrus sinensis) on Different Rootstocks in the Gharb Region (Northwestern Morocco). Annu. Res. Rev. Biol. 2017, 20, 1-11. [CrossRef]

23. Assouguem, A.; Kara, M.; Mansouri, I.; Imtara, H.; AlZain, M.N.; Mechchate, H.; Conte, R.; Squalli, W.; Farah, A.; Lazraq, A. Evaluation of the Effectiveness of Spirotetramat on the Diaspine Scale Parlatoria pergandii in Citrus Orchards. Agronomy 2021, 11, 1562. [CrossRef] 
24. Biche, M.; Siafa, A.; Adda, R.; Agagna, Y. Evaluation of Spirotetramat (Insecticide) on Scale Insects on Citrus in Algeria. Eval. Spirotetramat Insectic. Scale Insects Citrus Alger. 2011, 62, 123-131.

25. Nauen, R.; Reckmann, U.; Thomzik, J.; Thielert, W. Biological Profile of Spirotetramat (Movento)—A New Two Way Systemic (Amimobile) Insecticide against Sucking Pests Studies on the Susceptibility of Tuta Absoluta to Novel and Diamide Insecticides View Project Biological Profile of Spirotetramat (Movento $\left.{ }^{\circledR}\right)$. Bayer Crop. J. 2007, 61, 245-278.

26. Carrière, Y. Haplodiploidy, Sex, and the Evolution of Pesticide Resistance. J. Econ. Entomol. 2003, 96, 1626-1640. [CrossRef]

27. Kedia, A.; Prakash, B.; Kumar Mishra, P.; Singh, P.; Kishore Dubey, N. Botanicals as Eco Friendly Biorational Alternatives of Synthetic Pesticides against Callosobruchus spp. (Coleoptera: Bruchidae)—A Review. J. Food Sci. Technol. 2015, 52, $1239-1257$. [CrossRef]

28. Pan, D.; Dou, W.; Yuan, G.R.; Zhou, Q.H.; Wang, J.J.; Anderson, T. Monitoring the Resistance of the Citrus Red Mite (Acari: Tetranychidae) to Four Acaricides in Different Citrus Orchards in China. J. Econ. Entomol. 2020, 113, 918-923. [CrossRef] [PubMed]

29. Amirahmadi, M.; Shoeibi, S.; Abdollahi, M.; Rastegar, H.; Khosrokhavar, R.; Hamedani, M.P. Monitoring of Some Pesticides Residue in Consumed Tea in Tehran Market. J. Environ. Health Sci. Eng. 2013, 10, 2-7. [CrossRef] [PubMed]

30. Bajwa, U.; Singh Sandhu, K. Effect of Handling and Processing on Pesticide Residues in Food-A Review. J. Food Sci. Technol. 2014, 51, 201-220. [CrossRef] [PubMed]

31. Urbaneja, A.; Grout, T.G.; Gravena, S.; Wu, F.; Cen, Y.; Stansly, P.A. Citrus Pests in a Global World; Elsevier Inc.: Amsterdam, The Netherlands, 2020; ISBN 9780128122174.

32. Stanley, J.; Preetha, G. Pesticide Toxicity to Microorganisms: Exposure, Toxicity and Risk Assessment Methodologies; Springer Nature: Dordrecht, The Netherlands, 2016; ISBN 9789401777506. [CrossRef] 